\begin{abstract}
UNIVERSIDADE DE BRASÍLIA INSTITUTO DE CIÊNCIA POLÍTICA E DE RELAÇÕES INTERNACIONAIS DEPARTAMENTO DE RELAÇÕES INTERNACIONAIS IX CURSO DE ESPECIALIZAÇÃO EM RELAÇÕES INTERNACIONAIS

Área de Concentração: Política Externa
\end{abstract}

\title{
Política Externa do Brasil em Agricultura: O Papel da Embrapa na Cooperação Técnica
}

\author{
Aluno: Bonifácio Peixoto Magalhães \\ Orientadora: Profa. Cristina Yumie Aoki Inoue
}




\begin{abstract}
UNIVERSIDADE DE BRASÍLIA
INSTITUTO DE CIÊNCIA POLÍTICA E DE RELAÇÕES INTERNACIONAIS DEPARTAMENTO DE RELAÇÕES INTERNACIONAIS IX CURSO DE ESPECIALIZAÇÃO EM RELAÇÕES INTERNACIONAIS
\end{abstract}

Área de Concentração: Política Externa

\title{
Política Externa do Brasil em Agricultura: O Papel da Embrapa na Cooperação Técnica
}

\author{
Aluno: Bonifácio Peixoto Magalhães \\ Orientadora: Profa. Cristina Yumie Aoki Inoue \\ Monografia apresentada como \\ requisito parcial para a obtenção \\ do título de Especialista em \\ Relações Internacionais pela \\ Universidade de Brasília.
}




\section{Sumário}

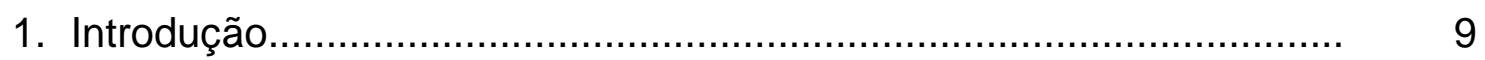

1.1 Política externa brasileira ........................................................... 10

1.2 Cooperação técnica internacional............................................. 12

1.3 Cooperação técnica prestada.................................................. 15

1.4 Cooperação técnica bilateral recebida........................................ 21

1.5 Cooperação técnica multilateral recebida................................... 21

2. A Embrapa no cenário agrícola nacional e internacional e sua agenda em cooperação técnica........................................................ 23

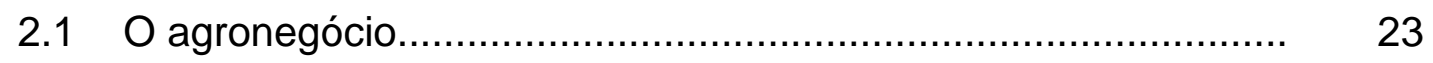

2.2 A cooperação técnica internacional do Brasil em agricultura e a inserção da Embrapa............................................................ $\quad 30$

3. A cooperação internacional na Embrapa .......................................... 32

3.1 A cooperação multilateral na Embrapa...................................... 33

3.1.1 O Agrofuturo............................................................ 34

3.1.2 O Instituto Interamericano de Cooperação para a Agricultura (IICA) ................................................. 35

3.1.3 Consórcio Iniciativa Amazônica para a Conservação e Uso Sustentável dos Recursos Naturais (IA)................ 36

3.2 Cooperação bilateral prestada na Embrapa …………….......... 37

3.2.1 Produção de alimentos básicos...................................... 37

3.2.2 Escritórios Regionais da Embrapa................................. 39

3.2.2.1 Embrapa África.............................................. 39

3.2.2.2 Embrapa Venezuela....................................... 41

3.3 Cooperação bilateral prestada e recebida................................... 42

3.3.1 Laboratórios da Embrapa no exterior - Labex............... 42

3.4 Cooperação bilateral recebida................................................... 43

3.4.2 O caso da soja...................................................... 44

3.4.1 O exemplo do programa de biodiversidade Brasil Itália. 
3.5 Considerações sobre as operações da cooperação técnica internacional na Embrapa .................................... 47

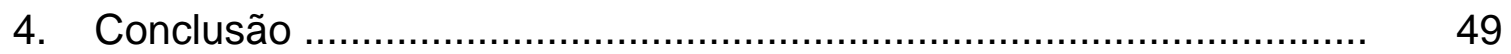

5. Referências bibliográficas....................................................... 54

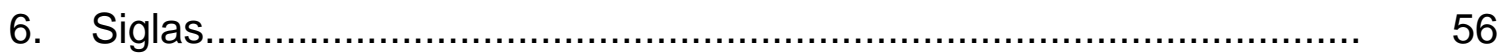


Dedico este trabalho aos meus filhos Ana, Augusto e Mariana, por seu amor incondicional e por compreenderem minha falta de tempo nos últimos meses. 


\section{Agradecimentos}

Aos professores e aos colegas do IX Curso de Especialização em Relações Internacionais pela convivência instrutiva e cordial do último ano. Em especial à Denize Bacoccina pela revisão do texto.

Aos colegas da Assessoria de Relações Internacionais, Embrapa, pelo incentivo e constante encorajamento. Especialmente ao Rodrigo Valadares e à Ana Cristina Cordeiro, pela revisão da primeira versão deste manuscrito. Ao Washinton Silva e à Ana Maria Gonçalves, Embrapa, e ao Jamil Macedo, IICA, pelas entrevistas e informações fornecidas. 


\section{Resumo}

O presente estudo teve como objetivo fazer uma análise da atuação da Embrapa em cooperação técnica internacional como parte da política externa brasileira em agricultura. O desempenho da Embrapa nessa área tem se concentrado no atendimento das demandas apresentadas pelos países. A Empresa deve realizar uma rigorosa revisão para migrar de uma postura reativa - e até mesmo passiva em alguns casos - para uma postura proativa. É imperativo a adoção de um sistema claro de atribuição de prioridades, para tratamento de cada país cooperante de acordo com os interesses da Embrapa e do Brasil.

Palavras-Chave: Política externa; cooperação técnica prestada; cooperação técnica recebida; cooperação bilateral; cooperação multilateral; pesquisa agrícola; ciência e tecnologia. 


\begin{abstract}
This study aimed to examine the performance of Embrapa in international technical cooperation as part of the Brazilian foreign policy in agriculture. The performance of Embrapa in this field has been centered in attending the demands presented by other countries. This procedure needs to be rigorously revised to migrate from a reactive - sometimes a passive - standing to a proactive standing. It is mandatory to have a clear system for prioritizing each cooperative country according to Embrapa and Brazilian needs.
\end{abstract}

Key-words: External policy; technical cooperation; technical cooperation received; bilateral cooperation; multilateral cooperation; agricultural research; science and technology. 


\section{Capítulo 1 Introdução}

\section{A Empresa Brasileira de Pesquisa Agropecuária} (Embrapa) foi criada há 34 anos e possui atualmente quarenta unidades descentralizadas, localizadas em diversos pontos do território brasileiro, e duas unidades avançadas (laboratórios virtuais ou remotos) no exterior. A Empresa coordena o Sistema Nacional de Pesquisa Agropecuária (SNPA), que congrega dezenove organizações estaduais de pesquisa e dezenas de unidades integradas, principalmente universidades.

A Embrapa tem tido uma atuação muito intensa na área de relações internacionais desde sua criação até os dias atuais. Num primeiro momento, essas relações tiveram o objetivo, sobretudo, de obter contribuições organizacionais, na capacitação científica de sua equipe, no dimensionamento de suas instalações, e na organização de seus programas de pesquisa. Hoje, o reconhecimento alcançado por suas realizações no desenvolvimento científico e tecnológico para dar suporte à agricultura tropical, desperta interesse de países e organizações internacionais para atuar como parceira em programas de transferência de tecnologia.

A atuação da Embrapa em cooperação internacional prestada e recebida, no entanto, ainda está bastante limitada. Há carência de uma estratégia bem definida para nortear as ações da Empresa. É patente a necessidade de adotar um sistema claro com prioridades para tratamento de cada país de acordo com os interesses brasileiros.

O objetivo deste estudo foi analisar a atuação da Embrapa em relação à política externa brasileira e seu papel nas atividades de cooperação técnica internacional. Foram feitas reflexões sobre os principais gargalos e possíveis soluções, e sobre uma possível 
priorização dos países com potencial para cooperação para atribuição de prioridade.

O presente trabalho foi estruturado em quatro partes. $\mathrm{Na}$ primeira, foi feita uma abordagem da política externa brasileira, contextualizando a cooperação técnica internacional no cenário global. $\mathrm{Na}$ segunda, foram abordados aspectos dos mercados agrícolas e do agronegócio no cenário da globalização em relação à cooperação técnica, além da inserção de Embrapa nesse contexto. Na terceira parte, foram discutidos os caminhos mais palpitantes da atuação da Embrapa no exterior envolvendo transferência de tecnologia. Especificamente, foi feita uma retrospectiva dos movimentos iniciais da cooperação técnica prestada e recebida, produção de alimentos básicos, etanol, biodiesel, laboratórios da Embrapa no exterior (Labex) e escritórios da Embrapa no exterior (Embrapa África e Embrapa Venezuela). Na quarta parte foi feita uma análise conclusiva abordando o significado da cooperação técnica prestada pela Embrapa e os benefícios dessa cooperação para a Empresa e para o Brasil.

\subsection{Política externa brasileira}

A política externa brasileira tem tradicionalmente sido voltada para o nacional desenvolvimentismo com pelo menos duas estratégias. Uma focalizava a promoção da autonomia nacional, com uma economia fechada. A outra preconizava a integração da economia do País aos mercados internacionais. Isso configurou uma disputa entre desenvolvimentismo nacional e liberalismo (Cervo, 1994). O enfoque liberal dominou o período de 1964 a 1969. Entre os anos 1969 e 1990 houve predomínio do desenvolvimentismo nacional na política externa brasileira. Com a redemocratização dos anos 1990 na América Latina o liberalismo voltou a orientar a política externa nacional (Vaz \& Inoue, 2008). 
Entre 1994 e 2002, no governo Fernando Henrique Cardoso, a política externa brasileira ficou centrada na modernização econômica e na melhoria das condições sociais do País. Buscou-se ampliar as relações do Brasil com outros grandes países em desenvolvimento e explorar oportunidades proporcionadas pelo processo de mudanças a nível mundial. Isso incluiu a integração de mercados, as novas tecnologias, a transferência de boa parte dos processos produtivos para empresas transnacionais, e o aumento do mercado financeiro e comercial $^{1}$.

O mais importante no governo Cardoso "eram a estabilidade econômica e a reinserção internacional do Brasil. Sua política externa tinha como foco principal mostrar-se um parceiro confiável dos países ricos e desenvolvidos, de onde viria o capital para a retomada do desenvolvimento. Isso levou a um alinhamento em alguns temas e ao silêncio em outros para não desagradar aos países centrais, sobretudo os EUA. Quando o real foi abalado pelas crises asiática e russa, os EUA coordenaram a ajuda do FMI"².

A postura externa do governo de Luiz Inácio Lula da Silva é de orientação globalizante, conforme afirmação de Antonio Carlos Peixoto $^{3}$. Mesmo assim houve uma tendência rumo à América do Sul e à África. Essas duas tendências não são conflitantes nem excludentes e podem apresentar benefícios recíprocos. O Brasil procurou estabelecer parcerias com o maior número de países e blocos regionais possíveis e buscou uma diversificação na sua estratégia global de política externa.

\footnotetext{
${ }^{1}$ http://www.psdb.org.br/biblioteca/era do real/30.pdf. Consultado em 8 de fevereiro de 2008.

${ }^{2}$ http://nelsonfrancojobim.blogspot.com/2007/06/poltica-externa-brasileira-do-barolula.html. Consultado em 5 de março de 2008.

${ }^{3}$ http://209.85.207.104/search?q=cache:tMWXm73FFw0J:www.redem.buap.mx/word/peix oto4.doc+pol\%C3\%ADtica+externa+brasileira\&hl=en\&ct=clnk\&cd=2\&client=firefox-a. Consultado em 7 de fevereiro de 2008.
} 
Qualquer desvio dessa estratégia globalizante poderia ter trazido resultados bastante negativos para a participação do País no âmbito internacional. Essa estratégia se aplica com muita propriedade aos esforços do País para impulsionar seu desenvolvimento científico e tecnológico por meio da cooperação internacional.

Com efeito, o Governo de Lula e o do argentino Néstor Kischner fizeram esforços para o relançamento do Mercosul e tentaram um acordo com a Comunidade Andina das Nações (CAN) - Bolívia, Peru, Equador, Colômbia e Venezuela - para criar a zona de livre comércio sulamericana proposta por Itamar Franco.

Concomitantemente, o Brasil aproximou-se de países desenvolvidos e em desenvolvimento como a China, a Índia e a África do Sul, e propôs a criação do Grupo dos 20, num esforço para combater o protecionismo agrícola dos países ricos na Organização Mundial do Comércio (OMC). Na realidade, esse foi um movimento político que buscava a abertura de novos mercados, especialmente no setor agrícola ${ }^{4}$.

\subsection{Cooperação técnica internacional}

O conceito de cooperação internacional entre comunidades técnico-científica internacionais não é novo nos países desenvolvidos e até mesmo nos países em desenvolvimento. Na prática, essa cooperação tem sido realizada de diferentes maneiras. Por meio de contatos pessoais, publicações, simpósios, reuniões de trabalho, e pesquisa cooperativa de alto nível.

Os países desenvolvidos (Estados Unidos, Inglaterra, França, Holanda, Alemanha, entre outros) incorporaram esse conceito com relativa eficácia. No entanto, vários outros países não adotaram a

\footnotetext{
${ }^{4}$ http://nelsonfrancojobim.blogspot.com/2007/06/poltica-externa-brasileira-do-barolula.html. Consultado em 5 de março de 2008.
} 
cooperação técnica. Este é o caso de países em desenvolvimento na África que, por diferentes razões, continuam mergulhados na pobreza e na miséria, e, em alguns casos, conduzem seus povos a uma situação de conflito e grande sofrimento (Ayensu, 1997).

Uma observação cuidadosa de países com desenvolvimento recente rápido, como é o caso de alguns na América Latina e Ásia, mostra que a adoção da cooperação técnica internacional tem conduzido a um progresso significativo nas suas economias e, de certa forma, no seu desenvolvimento social. A adoção de um programa de cooperação internacional por qualquer país depende de uma série de procedimentos a nível nacional (Ayensu, 1997).

A história da cooperação técnica internacional como instrumento de desenvolvimento coincide com aquela da segunda guerra mundial (Agência Brasileira de Cooperação - ABC, sem data). Naquela época, foram criados o Banco Mundial e o Fundo Monetário Internacional (Inoue \& Apostolova, 1995). A cooperação internacional regular foi delineada para englobar aspectos científicos, técnicos e tecnológicos pela Organização das Nações Unidas (ONU) devido à necessidade de reconstruir os países afetados pela guerra e de acelerar o desenvolvimento dos países menos industrializados.

Com esse objetivo a Assembléia Geral da ONU adotou a expressão "assistência técnica" em 1948. O objetivo era promover a transferência, em caráter não comercial, de técnicas e conhecimentos, mediante a execução de projetos em conjunto com atores de nível desigual de desenvolvimento, envolvendo peritos, treinamento de pessoal, material bibliográfico, equipamentos, estudos e pesquisas. Um aprimoramento dessa idéia foi feito em 1959, pela Assembléia Geral da ONU. Ficou decidido que o termo "assistência técnica" seria mudado para "cooperação técnica". Essa expressão seria mais adequada e 
determinaria uma relação de trocas, de interesses mútuos entre as partes, mesmo se tratando da existência de partes desiguais (Cervo, 1994).

O desenvolvimento da cooperação internacional, no entanto, foi prejudicado pelo reduzido número de instituições adequadamente capacitadas. Assim, era necessário priorizar a capacitação institucional. Buscou-se então, o aprimoramento de instituições nacionais com capacidade técnica em aspectos de administração pública, em planejamento, em ciência e tecnologia, e em gestão de programas governamentais, entre outros. Isso era um prérequisito para que os esforços empreendidos tivessem continuidade e para que os países a receberem cooperação se tornassem autônomos. Apesar da política de cooperação internacional ter se desenvolvido muito, o conceito inicial de "ajuda para o desenvolvimento" ou "ajuda para a autonomia" permanece vivo ainda hoje.

A definição de instrumentos e mecanismos adequados para a implementação da cooperação internacional foi objeto de atenção especial desde o início. A funcionalidade da cooperação internacional foi - e ainda é - garantida por meio de ajuda financeira, do apoio técnico, da formação de recursos humanos, dos processos de transferência de tecnologia, da doação de equipamentos e materiais, entre outros mecanismos. Mas,

A cooperação técnica não é mais a transferência unilateral de conhecimento, recursos e habilidades. Melhorar a efetividade desta requer que doadores e recebedores aprendam por meio da gestão de processos de mudança a melhorar ainda mais a formulação e implementação de suas atividades. O processo de desenvolvimento de capacidades requer habilidades humanas e institucionais apropriadas e adequadas para planejar e gerenciar processos de desenvolvimento econômico e social. Deve-se dar preferência a recursos humanos locais que são subutilizados em relação aos 'especialistas' estrangeiros (Lopes, 2005). 
O envolvimento de vários países desenvolvidos nos programas de cooperação, segundo a $A B C^{5}$, que tiveram continuidade mesmo após a etapa de reconstrução dos países mais afetados pela guerra foi bastante estimulado pela ONU. No entanto, à medida que os interesses comerciais não revelados se aprofundavam, os empecilhos ao livre fluxo dos conhecimentos técnicos começaram a ficar mais evidentes.

O estágio de desenvolvimento alcançado pelo Brasil, entre diversos países que vinham se beneficiando intensamente da cooperação internacional nas últimas décadas, provocou um aumento de demandas a instituições brasileiras, tanto por países interessados na sua experiência quanto por organismos internacionais.

É notório que o Governo brasileiro antevê ganhos para o País quanto a sua intermediação na cooperação internacional. O poder das atividades de cooperação internacional, tanto prestada quanto recebida, está na possibilidade de transformar os conhecimentos transmitidos em resultados políticos e econômicos para o Brasil.

\subsection{Cooperação técnica prestada}

A transferência de tecnologia via cooperação técnica é um dos instrumentos primordiais para apoiar o crescimento. Por outro lado, a iniciativa da Embrapa de apoiar alguns países africanos está respaldada no art. $4^{\circ}$, inciso XI da Constituição Federal que dispõe que o Brasil "regese nas suas relações internacionais pelo princípio da cooperação entre os povos".

Ao mesmo tempo em que as atividades desenvolvidas pela Embrapa seguem os princípios da Constituição Federal, uma visão humanitária tem prevalecido na cooperação prestada buscando-se,

\footnotetext{
${ }^{5}$ http://www.abc.gov.br/ct/historico ct.asp. Consultado em 9 de fevereiro de 2008.
} 
primordialmente, atender às demandas na área de produção de culturas alimentares.

Embora haja esforço redobrado tanto do prestador da cooperação quanto do recebedor, as dificuldades encontradas para desenvolver tais atividades são marcantes. Depara-se constantemente com problemas estruturais nos países recebedores da cooperação, tais como a ausência de infra-estrutura mínima como água, energia constante, estradas e ausência de mercado consumidor para escoamento da produção. Some-se a isso as dificuldades conjunturais como a fragilidade nas redes de apoio financeiro para dar sustentação às iniciativas, a carência de base institucional dos contrapartes para dar andamento às atividades planejadas e a necessidade de capacitação do corpo técnico disponível.

A mesma preocupação aplica-se à cooperação técnica prestada pelo Brasil a outros países mediada pela $A B C$. A missão da Cooperação Técnica entre Países em Desenvolvimento (CTPD) nacional é definida como a de contribuir para o adensamento das relações do Brasil com os países em desenvolvimento, a geração, disseminação e utilização de conhecimentos técnicos, a capacitação de seus recursos humanos e o fortalecimento de suas instituições.

O Governo brasileiro, reconhecendo a importância que a cooperação técnica internacional havia representado para o desenvolvimento nacional, considerou que o Brasil deveria dar um retorno compatível com os benefícios dela obtidos e colocou sua experiência à disposição dos países interessados.

O Brasil tem estabelecido inúmeros projetos de cooperação bilateral e multilateral, até mesmo sob a forma de cooperação triangular. A cooperação triangular Sul-Sul, por exemplo, que envolve dois 
países em desenvolvimento e um país desenvolvido ou uma organização internacional. No entanto, geralmente não envolve cooperação financeira. É um tipo de cooperação que visa ao desenvolvimento dos países do Sul e seu fortalecimento por meio de intercâmbio de conhecimento e experiências.

Como possui larga experiência em agricultura tropical e em cooperação técnica, o Brasil pode ser muito útil aos países menos desenvolvidos, por meio da cooperação triangular (Verenhitach et al, 2007). A participação do Brasil nesta modalidade de cooperação é resultante de uma nova orientação do Governo Lula. Nossa política externa é praticada no sentido de cooperar técnicamente com outros países menos favorecidos, com os recursos que o País possa disponibilizar.

O desenvolvimento de programas de assistência e cooperação brasileiros tem aumentado e amadurecido e o governo tem procurado a introdução de maior coerência por meio de instituições coordenadoras como a ABC. Entretanto, a formulação e a implementação de programas de desenvolvimento mantém-se largamente fracionada e descentralizada, com numerosos locais de atividades e execução de programas (Vaz \& Inoue, 2008). A inexistência de uma instituição centralizada com responsabilidade global sobre os programas de assistência e desenvolvimento significa que é virtualmente impossível calcular o montante de recursos realmente alocados para essas atividades.

Apesar disso há uma determinação de prioridades setoriais de programas para cooperação técnica entre países em desenvolvimento. Esses programas incluem as áreas de agricultura e ciência e tecnologia. Mas os resultados práticos dessa cooperação técnica ainda são muito tímidos e não podem ser avaliados. 
Como vários outros países, o Brasil inseriu em sua política externa um forte viés de cooperação com a África. Isso foi rapidamente assimilado pelas instituições governamentais brasileiras em função, inclusive, dos laços históricos presentes nas relações exteriores do Brasil com os países africanos. Segmentos como o de agricultura, educação, transportes e saúde, entre outros, transformaram-se em áreas importantes de cooperação técnica.

Nessa definição, a agricultura como fonte de produção de alimentos e combate à fome, destaca-se como o eixo principal da cooperação brasileira aos africanos. Hoje $70 \%$ da população africana ancora a economia local no setor agropecuário.

A África é atualmente um dos maiores desafios para o desenvolvimento global. Enquanto alguns países apresentaram um crescimento anual, o número interno anual de pobres e famintos duplicou nas duas últimas décadas Se esta tendência não for revertida, o continente não será capaz de atingir um dos objetivos estabelecidos pelo Programa de Desenvolvimento do Milênio das Nações Unidas (Millennium Development Goal, MDG) que é, entre outros, o de "erradicar a extrema pobreza e a fome" reduzindo pela metade, até 2015, a proporção da população que passa fome e que sobrevive com renda inferior a um dólar por dia.

É evidente que a agricultura é um instrumento facilitador para atingir um dos objetivos das Nações Unidas. A Embrapa desenvolve há mais de três décadas pesquisas destinadas a atender as regiões tropicais, onde os países africanos também estão inseridos. A similaridade de solo, clima e vegetação, aliada aos conhecidos laços históricos entre o Brasil e o continente africano traçam um cenário que aponta para a obtenção de resultados positivos na atividade de transferência de tecnologias agrícolas adaptáveis àquela região. 
Na África há mais de 20 anos, a Embrapa vem trabalhando em parceria com vários países, em especial os de língua portuguesa Angola, Moçambique, Guiné-Bissau, Cabo Verde e São Tomé e Príncipe. Inicialmente, as atividades concentravam-se em capacitação de técnicos desses países em centros de pesquisa da Embrapa com financiamento de terceiros países. Posteriormente, as parcerias foram ampliadas em função das demandas oriundas dos países de língua inglesa e francesa.

Nesse processo, o Ministério das Relações Exteriores (MRE) e a $A B C$ constituíram-se contrapartes relevantes tendo em vista que a Embrapa passou a ser executora da maioria dos projetos de cooperação na área agrícola firmados entre o Brasil e os países africanos via MRE e $A B C$. Paralelamente, a Embrapa passou a fazer parte das Comissões Mistas lideradas pelo MRE com os países africanos nas áreas de agropecuária e ciência e tecnologia.

Por outro lado as representações diplomáticas desses países no Brasil e as instituições de governo dos países africanos, respaldados pelos Acordos Quadros e respectivos Ajustes Complementares assinados entre os Ministérios das Relações Exteriores, passaram a contatar a Embrapa diretamente e a demandar atividades de transferência de tecnologias ou de apoio ao desenvolvimento institucional de seus institutos de pesquisa.

Também contribuíram para a aproximação e divulgação da Embrapa junto aos países africanos organismos internacionais como a Organização das Nações Unidas para a Alimentação (FAO), o Banco Mundial, os institutos vinculados ao sistema do Grupo Consultivo em Pesquisa Agrícola Internacional (CGIAR), o MRE e a $A B C$, entre outros.

Mais recentemente o Governo Federal adotou uma política externa mais agressiva de apoio à África e convocou as instituições 
governamentais a intensificarem os relacionamentos com as instituições africanas correlatas. Países como os cinco de língua portuguesa já citados além de Namíbia, Benin, Nigéria, Senegal, África do Sul, entre outros, passaram a interagir com a Embrapa, seja em ações pontuais, seja demandando projetos estruturados de cooperação técnica.

Em meados dos anos 1990 a Embrapa já estava inserida em um ambiente institucional onde demandas por cooperação técnica e científica advindas da África chegavam até a Empresa por diferentes canais e com alta expectativa de resposta positiva por parte dos demandantes. As demandas foram então potencializadas. A Embrapa, além de atender os tradicionais programas trilaterais de capacitação de técnicos, ampliou sua atuação enviando técnicos para consultorias de curta duração e assistência técnica e, ao mesmo tempo, promoveu doação de materiais genéticos e bibliográficos.

Apesar de um cenário na maioria das vezes frágil para o estabelecimento de um programa consistente de assistência técnica e transferência de tecnologia, a Embrapa busca transformar as dificuldades em desafios e estes em projetos concretos com inicio, meio e fim. Sua atuação plena, no entanto, é limitada pela falta de uma dotação orçamentária planejada e específica por parte do Governo.

\subsection{Cooperação técnica bilateral recebida}

Historicamente, as atividades de cooperação técnica bilateral recebida desenvolvidas entre o Brasil e países mais avançados têm servido como instrumento de desenvolvimento do País e para a construção da autonomia nacional nos temas envolvidos. Isso ocorreu com o caso das adaptações de variedades da soja em cooperação principalmente com os Estados Unidos. Os benefícios dessa cooperação 
para o Brasil são inquestionáveis. O Brasil é hoje o maior exportador mundial de soja.

A ABC coordena os esforços do Brasil para viabilizar o atendimento das demandas, encaminhando projetos aos países doadores mais operantes. Os países que têm sido mais ativos nessa área são o Japão, a Alemanha, a França, o Reino Unido, o Canadá e a Espanha6 ${ }^{6}$.

\subsection{Cooperação técnica multilateral recebida}

A cooperação técnica multilateral recebida é normalmente praticada com o envolvimento de organismos internacionais e instituições nacionais. Os custos dessa cooperação são cobertos com recursos aportados pelos organismos internacionais e instituições nacionais.

Um exemplo importante de cooperação técnica multilateral recebida exercitada pelo Brasil é o projeto de manejo sustentável de florestas na Amazônia brasileira desenvolvido pela Embrapa com apoio da Organização Tropical Internacional da Madeira (International Tropical Timber Organization, ITTO) (Fonseca, 2007).

A cooperação internacional na Embrapa é fundada na reciprocidade ou no interesse mútuo em que a Empresa tanto é beneficiária quanto prestadora de cooperação técnica e científica. É uma atividade de fundamental relevância, que envolve ações de apoio à política externa do Governo brasileiro e ações de interesse mais específico e direto da própria Embrapa.

A operacionalização da cooperação técnica internacionnal na Embrapa não tem sido fácil. A maior inquietação é que a Empresa não tem uma estrutura operacional à altura da missão que recebe do

\footnotetext{
${ }^{6}$ Para maiores detalhes vide Fonseca (2007)
} 
Governo. Há um número muito reduzido de técnicos da equipe responsável por uma sistema de cooperação cada vez mais demandante. A equipe da Assessoria de Relações Internacionais da Embrapa é tão reduzida que conta com apenas um técnico para acordos bilaterais com países desenvolvidos da América do Norte, Europa e Ásia, um para relações multilaterais, um para acordos com América Latina e um para acordos com a África. 


\section{Capítulo 2}

\section{A Embrapa no cenário agrícola nacional e internacional e sua agenda em cooperação técnica}

Um dos efeitos da globalização é a redução expressiva do papel dos Estados no plano econômico. Além disso, os mercados globais estão cada vez mais integrados, com um poder de competição muito maior. Entretanto, as variáveis relacionadas ao meio ambiente terão peso ainda maior nas operações econômicas.

Bastante curiosa é participação do Estado na agricultura tanto em países desenvolvidos quanto em países em desenvolvimento. Nos países desenvolvidos há uma proteção por meio de subsídios de modo a manter estabilizados os preços e a renda dos produtores rurais. Já nos países em desenvolvimento, inclusive no Brasil, não há uma política agrícola definida para apoiar o produtor rural envolvendo financiamento e sistema de seguro rural, por exemplo. A nível global, essa falta de uma política agrícola adequada retarda o crescimento ecômico e acarreta enorme sofrimento às populações dos países em desenvolvimento. Todas essas considerações afetam de alguma forma 0 agronegócio.

\subsection{0 agronegócio}

Os mercados do agronegócio sofreram os efeitos das mudanças econômicas provocadas pela globalização. Isso é particularmente verdadeiro na definição das tendências observadas nos anos 1990 que orientaram a formulação de políticas macroeconômicas nos anos seguintes, com profundos efeitos sobre o agronegócio doméstico e internacional. 
No caso do Brasil, o agronegócio é baseado na agricultura que envolve uma série de atividades extremamente relevantes inclusive no setor agroindustrial. Esse setor está fortemente ligado ao setor agrícola incluindo fertilizantes, agrotóxicos, máquinas e equipamentos agrícolas, crédito rural, transportes e pesquisa agropecuária.

Os resultados científicos e tecnológicos alcançados pelas instituições vinculadas ao SNPA, segundo o Relatório Final do PRODETAB ${ }^{7}$, "têm justificado plenamente os investimentos realizados e deram impulso ao agronegócio brasileiro, que tem crescido de forma consistente nas últimas décadas. O patamar de crescimento, no entanto, estaria muito aquém das necessidades e da capacidade do País de produzir alimentos, gerar riquezas e promover o desenvolvimento socioeconômico. Nitidamente, faltam mais investimentos em pesquisa. $O$ Brasil investe menos de 1\% do Produto Interno Bruto (PIB) agrícola em pesquisa agropecuária, algo em torno de um milhão de reais, enquanto países como o Canadá investem até 5,3\% do seu PIB agrícola."

O agronegócio brasileiro contribui com cerca de 28\% para o PIB e emprega a maior parte da população economicamente ativa do País. O agronegócio nacional pode crescer ainda mais uma vez que

\footnotetext{
7 Projeto de Apoio ao Desenvolvimento de Tecnologias Agropecuárias para o Brasil. O PRODETAB foi um projeto negociado entre o governo brasileiro e o Banco Mundial e administrado pela Embrapa. O total de recursos alocados foi de 120 milhões de dólares americanos, para ser usado em pesquisa, desenvolvimento e transferência de tecnologias agrícola, florestal e agroindustrial. O projeto foi desenvolvido entre 1997 e 2005. O PRODETAB teve um desempenho muito positivo e trouxe no seu escopo uma inovação estratégica da sistemática de alocação dos recursos para a pesquisa agrícola com o estabelecimento de um Sistema Competitivo para a alocação de recursos para projetos de P\&D. Este projeto introduziu uma diferença qualitativa, aumentou a pesquisa estratégica, aplicada e básica. Promoveu a pesquisa estratégica, aplicada e ampliou as perspectivas de transferência e adoção de tecnologia com o envolvimento de produtores e organizações comunitárias na concepção e execução dos projetos de pesquisa. Fontes: Entrevista com Ana Maria Gonçalves, Embrapa/Assessoria de Relações Internacionais; Relatório Final - PPRODETAB - Embrapa / Coordenadoria de Cooperação Internacional. 57p. 2006; e

http://209.85.165.104/search?q=cache:ZplxNaYoxmMJ:www.worldbank.org/html/aftsr/ap pend41.pdf+prodetab\&hl=en\&ct=clnk\&cd=1\&client=safari. Consultado em 12 de março de 2008) .
} 
dispomos de cerca de 55 milhões de hectares explorados na agricultura e pecuária, com uma parte considerável degradados. Boa parcela dessa área pode ser reincorporada ao sistema produtivo graças ao programa de recuperação de áreas degradadas desenvolvido pela Embrapa. Com esse programa é possível recuperar uma área improdutiva dentro de até três anos por meio da exploração do sistema integrado de lavoura, agricultura e pecuária. A vantagem ambiental desse sistema está na possibilidade de não abrir (desmatar) ou reduzir a abertura de novas áreas de cerrado. Vale lembrar que dispomos de uma área total de mais de 210 milhões de hectares - 24\% do território nacional - da região de cerrados. Essa área contém mais de 80 milhões de hectares ainda intactos que podem ser preservados com auxílio do programa de recuperação de áreas degradadas desenvolvido pela Embrapa.

Essa vantagem permite ao Brasil se apresentar no cenário mundial como um grande competidor. As principais razões estão ligadas ao fato de que o Brasil possui a maior área de terra agricultável do mundo. A política externa ainda se ressente de um eficaz sistema de promoção comercial e de uma diplomacia comercial mais dinâmica e agressiva.

Países com expressivo nível de exportação utilizam um sistema de comercialização bastante avançado, financiando exportação e promovendo marketing. Já com relação às exportações agrícolas,

... devido às características cíclicas da agricultura e ao elevado grau de competitividade dos mercados agrícolas, esses mecanismos são cruciais. A política de marketing envolveria, em primeiro lugar, a alocação de recursos destinados exclusivamente à promoção dos produtos brasileiros no exterior, com base em dois objetivos: ampliação dos mercados tradicionais e criação de novos mercados. A outra categoria envolve o estabelecimento de uma diplomacia comercial mais agressiva, atuando concretamente 
para eliminar as barreiras comerciais existentes contra produtos agrícolas brasileiros em alguns países ${ }^{8}$.

Igualmente importantes são as considerações ambientais para a produção de biocombustíveis, principalmente o etanol. É necessário debater intensamente a ampliação da nossa matriz energética. Os efeitos do aumento da área plantada deverão ser considerados. Ao mesmo tempo, busca-se uma alternativa técnica para que um provável aumento da área plantada para incorporar as culturas oleaginosas que dão origem ao biocombustível produza o menor impacto possível no meio ambiente.

O etanol no Brasil é produzido a partir da cana-de-açúcar nas regiões Centro-Sul, Norte e Nordeste. O Brasil e os Estados Unidos são atualmente os maiores produtores de etanol. Os Estados Unidos extraem esse produto do milho.

O Brasil já possui uma matriz energética com significativa participação de energias renováveis, tendo acumulado importante experiência na produção de álcool como combustível, tanto anidro como hidratado. A ampliação dessa participação na matriz, a partir do desenvolvimento da agroenergia, propicia a oportunidade de executar políticas, de cunho social, ambiental e econômico, além de alinhar-se com ações de caráter estratégico no âmbito internacional.

No curto e no médio prazo, a função da agroenergia será a de propiciar uma transição mais tranqüila rumo a uma matriz energética com maior participação da energia renovável, inclusive ampliando o horizonte de uso das atuais fontes de carbono fóssil. Subsidiariamente, o desenvolvimento da agroenergia, no Brasil, promoverá importante

${ }^{8}$ http://www.itamaraty.gov.br/cdbrasil/itamaraty/web/port/economia/agric/caminhos/index. htm. Consultado em 27 de fevereiro de 2008. 
aumento de investimentos, empregos, renda e desenvolvimento tecnológico e será uma oportunidade para atender parte da crescente demanda mundial por combustíveis de menor impacto ambiental. Essa visão de futuro é plenamente aplicável ao Brasil, que poderá se constituir no maior provedor individual de energia renovável no mercado internacional de bioenergia.

O biodiesel é um combustível líquido derivado de biomassa renovável, que substitui total ou parcialmente o óleo diesel de petróleo em motores de ignição por compressão, automotivos (caminhões, tratores, camionetas, automóveis), transportes (aquaviários e ferroviários) e estacionários (geradores de eletricidade). O biodiesel pode ainda substituir outros tipos de combustíveis fósseis na geração de energia, a exemplo do uso em caldeiras ou em geração de calor em processos industriais. É produzido a partir de diferentes matérias-primas, tais como óleos vegetais diversos (mamona, dendê, soja, girassol, amendoim, algodão), gorduras animais, óleos e gorduras residuais, por meio de diversos processos. O biodiesel pode ser usado puro ou misturado ao diesel em diversas proporções.

No âmbito internacional, barreiras tecnológicas e comerciais podem dificultar a colocação do biodiesel nos mercados externos, em especial dos Estados Unidos e da União Européia, onde predomina a transesterificação metílica a partir de um seleto conjunto de oloeaginosas (soja e canola). Isso é relevante para o aproveitamento do diferencial positivo do Brasil no segmento agrícola, que dispõe de uma grande diversidade de matérias-primas, com diferentes potencialidades regionais. Engloba tanto culturas já tradicionais, como a soja, o amendoim, o girassol, a mamona e o dendê, quanto para alternativas novas, como o pinhão manso, o nabo forrageiro e uma grande variedade de oleaginosas a serem exploradas (Crestana \& Magalhães, 2007). 
O cultivo de matérias-primas e a produção industrial têm grande potencial de geração de empregos, promovendo, dessa forma, a inclusão social. Para estimular ainda mais esse processo, o Governo Federal instituiu um modelo tributário específico, com a criação do selo "Combustível Social" e a instituição de níveis diferenciados de desoneração tributária em função do aproveitamento combinado da agricultura familiar e do agronegócio na cadeia produtiva.

O desenvolvimento do biodiesel continua um desafio. Nos aspectos tecnológicos da produção agrícola, são prioridades a identificação e seleção de oleaginosas, o aumento de sua produtividade em óleos, hoje muito baixo e o desenvolvimento de sistemas de produção rentáveis com preservação dos recursos naturais. Na área industrial, a transformação de óleos vegetais em biodiesel ainda necessita de aprimoramentos, como o aumento da eficiência extrativa, a desintoxicação de tortas, como da mamona e uma melhor utilização de sub-produtos, como a glicerina. Apesar de grande pressão internacional, há necessidade de uma maior estruturação do setor produtivo do biodiesel no Brasil antes que as ações de cooperação técnica sejam implementadas.

A forte busca de substituição do petróleo por combustíveis alternativos leva a um enorme esforço para o aprimoramento de tecnologias de aperfeiçoamento para explorar a diversidade de plantas agricultáveis como fontes de combustíveis biológicos. Para isso, tem sido empreendido um grande esforço para criação de um mercado global de biocombustíveis. Busca-se também uma integração da matriz energética brasileira com a de nossos vizinhos sul-amerericanos.

Em resposta a essas indagações, em 2007 foi inaugurada a Embrapa Agronergia. Essa unidade de pesquisa da Embrapa assumiu a coordenação de uma rede nacional de pesquisas em agroenergia, com 
participação de universidades e instituições de pesquisas públicas e privadas, com o intuito de manter o Brasil à frente da produção de bioenergia.

Os principais temas estratégicos da Embrapa Agronergia são: i) Integração de políticas públicas e arranjos privados; ii) implantação de sistemas de produção agrícola sustentáveis que supram a eficiência de processos industriais; iii) estudos comparativos sobre agricultura de alimentos e agricultura de energia; iv) estudos detalhados de competitividade e oferta de longo prazo das principais commodities agroenergéticas, no Brasil e no mundo; v) balanço energético de culturas alternativas para biocombustíveis, com enfoque regional; vi) produtividade agrícola da água em termos energéticos (nos curto e longo prazos); e vii) estruturar redes de Pesquisa, Desenvolvimento e Inovação (PD\&l) e de negócios tecnológicos, com enfoques regionais ${ }^{9}$.

As perspectivas de expansão do agronegócio brasilieiro e que o mercado mundial continue a absorver grande parte da produção nacional são muito promissoras. Hoje, o Brasil é o maior o produtor mundial de açúcar, suco de laranja e café. É o maior exportador de açúcar, suco de laranja, café, soja, carne e frango.

Existe possibilidade de ampliação dessa base de produção para atender o crescimento da demanda mundial de vinho, lácteos, óleo de palma, frutas, carnes e soja. Outro setor com crescimento vertiginoso é a agricultura natural ou biológica. O Brasil poderá desenvolver sua produção do "boi verde", além de outros produtos orgânicos.

O segmento mundial de mercado que mais chama a atenção é o asiático devido ao crescimento principalmente da China, além da abertura do mercado japonês ao comércio exterior. O agronegócio

\footnotetext{
${ }^{9}$ http://www.cnpae.embrapa.br/temas-estrategicos. Consultado em 10 de março de 2008.
} 
brasileiro pode ser afetado por questões ligadas ao meio ambiente. Inegavelmente, o aquecimento global e o uso sustentável da água despertam grande interesse das comunidades internacionais ligadas à proteção ambiental.

\subsection{A cooperação técnica internacional do Brasil em agricultura e a inserção da Embrapa}

As últimas duas décadas têm sido marcadas por intensa movimentação internacional. Isso tem resultado em importantes e positivos reflexos na formação de blocos continentais e, principalmente, nas ações de ajuda mútua entre os países mais desenvolvidos e aqueles em fase de desenvolvimento.

Mesmo com uma equipe extremamente limitada na Assessoria de Relações Internacionais, a Embrapa tem estabelecido ações de cooperação técnica com vários países. Em cooperação bilateral, foram assinados 68 acordos com 37 países, envolvendo 64 instituições. No momento, a Embrapa tem acordos multilaterais com 20 instituições internacionais.

O potencial de contribuição da Embrapa para 0 desenvolvimento da agricultura tropical é inegável. São muitas as tecnologias desenvolvidas que podem ser adaptadas a países com características semelhantes. Dentre os muitos avanços podemos pinçar alguns na área de biotecnologia: i) desenvolvimento do primeiro clone animal no Brasil (Vitória); ii) plantas produtoras de hormônio de crescimento e insulina; iii) variedade de mamão resistente a infecção causada por vírus; iv) desenvolvimento de variedade resistente de feijoeiro ao mosaico dourado; v) variedade de soja resistente a herbicida; vi) desenvolvimento de controle de insetos pragas em algodoeiro; vii) 
seleção de raças de Bacillus thuringiensis para controle de insetos pragas; viii) novos biomateriais; e ix) novas moléculas ou processos.

A cooperação técnica internacional brasileira em agricultura é mediada principalmente pela $A B C$. Considerando todas as áreas de cooperação desenvolvida pela $\mathrm{ABC}$, cerca de $50 \%$ dos projetos em execução contam com a participação direta da Embrapa. Especificamente em agricultura, 95\% dos projetos são executados em cooperação com a Embrapa ${ }^{10}$. Isso torna evidente a grande responsabilidade da Empresa e a necessidade de melhorar a estrutura do sistema de cooperação internacional existente.

\footnotetext{
${ }^{10}$ Informações cedidas por Washington Silva, Chefe da Coordenadoria de Prospecção e
} Inovação, Assessoria de Relações Internacionais, Embrapa. Brasília, fevereiro de 2008. 


\section{Capítulo 3}

\section{A cooperação internacional na Embrapa}

O reconhecimento da tecnologia agropecuária desenvolvida para os trópicos, validada pelos expressivos índices de produtividade da agropecuária brasileira, atravessou as fronteiras do País e cria expectativas no mundo em desenvolvimento. O conhecimento gerado pela Embrapa tornou-se um fator decisivo no estabelecimento de uma agricultura moderna em outros países em desenvolvimento, podendo causar repercussões positivas na diminuição da fome e na redução dos índices de pobreza, objetivos das Nações Unidas para o presente milênio por meio do Programa de Desenvolvimento do Milênio.

Existe atualmente a abertura nos organismos internacionais, nas agências de alguns países industrializados, da agência governamental responsável pela implementação da política brasileira de cooperação internacional - a ABC - e mesmo nos países que pleiteiam o apoio, para pagamento dos custos decorrentes da cooperação. Apesar desses avanços inegáveis, a cooperação praticada pela Embrapa deve ser otimizada para incluir um sistema de acompanhamento e avaliação de projetos mais eficiente.

O interesse pela tecnologia agrícola desenvolvida pela Embrapa é demonstrado pelo grande número de documentos assinados por diferentes administrações da Empresa, com diversos países em desenvolvimento. No passado, a maioria dos instrumentos de cooperação não saía do papel por absoluta falta de recursos. Hoje a situação é melhor, mas muitos projetos de cooperação técnica ainda continuam sendo elaborados e não executados. Muitos são executados mas não têm andamento satisfatório. 
A contribuição da Embrapa à política externa brasileira como cooperação técnica multilateral, cooperação prestada e recebida será abordada em forma dos tópicos considerados mais relevantes a seguir.

\subsection{A cooperação multilateral na Embrapa}

A constituição de novos organismos e iniciativas internacionais e multilaterais são ações de grande impacto e significado nas quais a Embrapa tem ativa e importante participação. Exemplos significativos são o Fórum Índia-Brasil-África do Sul (IBAS), a Nova Parceria para o Desenvolvimento Africano (NEPAD), a grande abertura e flexibilização da Comunidade Européia, a Cúpula dos Países da América do Sul com os Países Árabes (em construção), o desenho da cooperação trilateral atualmente proposta pela FAO e pela Agência Japonesa de Cooperação Internacional (JICA) para a África e para a América Latina, além da nova abordagem do CGIAR. Hoje a Embrapa tem acordos assinados com 20 países para cooperação multilateral.

Num possível exercício de cooperação Sul-Sul, vale a pena refletir sobre os movimentos da África do Sul, da China e da Índia. Esses países, à semelhança do Brasil, investiram pesadamente em ciência e tecnologia para o agronegócio e são parceiros ideais para o estabelecimento de cooperação mútua.

É interessante ao Brasil, por exemplo, germoplasmas de citros e soja dos quais a China é reconhecidamente o centro de origem. Aos chineses, o arroz de sequeiro, amendoim e outras plantas originárias do ambiente brasileiro. Os indianos querem conhecer os processos de produção agrícola brasileiros e os avanços na agricultura familiar. Com a África do Sul, o interesse brasileiro é nas raças de caprinos altamente 
produtivas e o deles na alta produtividade de nossa pecuária de carne (Barbosa \& Costa, 2005).

A negociação e o monitoramento de importantes ações propostas no âmbito de grandes programas especiais internacionais, com o suporte financeiro do Banco Interamericano de Desenvolvimento (BID) e o Banco Mundial (BIRD), demandaram estratégias na execução do PRODETAB, do Programa de Apoio ao Desenvolvimento de Novas Empresas de Base Tecnológica Agropecuária e à Transferência de Tecnologia (PROETA) ${ }^{11}$ e nos desdobramentos para internalização do Programa de Inovação Tecnológica e Novas Formas de Gestão da Pesquisa Agropecuária (Agrofuturo). Acrescente-se a isso, os esforços de integração regional realizados pelo Consórcio Iniciativa Amazônica para a Conservação e Uso Sustentável dos Recursos Naturais, referido normalmente com Iniciativa Amazônica (IA).

\subsubsection{O Programa de Inovação Tecnológica e Novas Formas de Gestão da Pesquisa Agropecuária (Agrofuturo)}

O Agrofuturo é um programa com o objetivo geral de contribuir para melhorar a competitividade, a eficiência e a eqüidade do setor agropecuário brasileiro, por meio da geração e transferência de conhecimentos e tecnologias. Foi iniciado em 2007, com término previsto para 2012. Os objetivos específicos do programa são: i) fortalecer a capacidade de pesquisa da Embrapa para diversificar as exportações brasileiras com produtos de alta qualidade e valor agregado, com maior participação do setor privado; ii) modernizar e atualizar os recursos para servir áreas estratégicas de pesquisa; iii) aumentar o acesso aos mercados e a integração da produção familiar às cadeias do agronegócio;

\footnotetext{
11 O PROETA é um programa proposto como fruto de diversos estudos e debates entre a administração, as equipes de pesquisa e desenvolvimento e as áreas de negócios, como opção para dinamizar a transferência de tecnologia. É uma proposta de criação de empreendimentos de tecnologia agropecuária, utilizando-se o processo de incubação de empresas que conta com o
} 
e iv) fortalecer a cooperação técnico-científica nos âmbitos regional e internacional.

O Agrofuturo conta com um orçamento total de 60 milhões de dólares americanos. Esses recursos foram obtidos por meio de um empréstimo do BID (33 milhões) e da contrapartida do Governo brasileiro (27 milhões) e foram alocados de acordo com prioridades préestabelecidas. Como o programa ainda está na sua fase inicial não é possível fazer uma avaliação de seu desempenho ${ }^{12,13}$.

\subsubsection{O Instituto Interamericano de Cooperação para a Agricultura (IICA)}

A participação do IICA tem sido muito positiva nas três últimas décadas de sua história. O IICA responde a um mandato de Chefes de Estado e de Governo e da Assembléia Geral das Organizações dos Estados Americanos (OEA), além dos ministros de agricultura do hemisfério.

\footnotetext{
apoio financeiro do Fundo Multilateral de Investimentos (Funim) e do BID (http://www.cnpat.embrapa.br/proeta/apresentacao.html. Consultado em 12 de março de 2008.

12 Prioridades para alocação de recursos: i) Sistema competitivo de pesquisa e desenvolvimento (US\$ 14,175 milhões). Trata-se de tecnologias de apoio a cadeias agro-exportadoras. Visa consolidar ou desenvolver oportunidades de exportação para produtos novos e inovadores das cadeias de carnes, couros e peles, frutas e hortaliças, bioenergia e produtos de aqüicultura; ii) Fortalecimento de capacidades em áreas estratégicas (US\$ 33,151 milhões). Inclui recursos naturais; biotecnologia e biossegurança; boas práticas de laboratório e campo; recursos genéticos; avaliação de impactos e eficiência; propriedade intelectual; e sistemas de informação e comunicação; iii) Núcleo piloto de informação e gestão tecnológica para agricultura familiar (US\$ 3,000 milhões). O objetivo é promover a oferta de tecnologias para atender as necessidades da agricultura familiar. Serão implantados três núcleos-piloto em Aurora (PA), Valente (BA) e Dourados (MS), com apoio de organismos como o MDA, Incra, Sebrae, associações de produtores e unidades da Embrapa localizadas nas respectivas regiões; iv) Integração regional e internacional (US\$ 8,673 milhões). Visa fortalecer as relações entre o sistema de desenvolvimento tecnológico brasileiro e os parceiros internacionais por meio de acordos pré-estabelecidos utilizando os instrumentos de cooperação como o Labex, o CGIAR, o Programa Cooperativo para o Desenvolvimento Tecnológico Agropecuário do Cone Sul (Procisul) e o Programa Cooperativo de Investigação e Transferência de Tecnologia para os Trópicos Sul (Procitrópicos).

${ }_{13}$ Informações cedidas por Washington Silva, Chefe da Coordenadoria de Prospecção e Inovação, Assessoria de Relações Internacionais, Embrapa. Brasília, fevereiro de 2008.
} 
As atividades desenvolvidas pelo IICA em pesquisa e desenvolvimento, numa estimativa conservadora, contam com recursos anuais diretamente aplicados pelos PROCIs (Procitrópicos e Procisul) da instituição da ordem de três milhões de dólares americanos. Nesses recursos estão incluídas contribuições do IICA, dos países e dos projetos de pesquisa. Esse montante poderia ser acrescido de 15 a 20 milhões de dólares americanos se considerarmos os projetos administrados pelas representações nos países membros voltados para atividades de PD\&I ${ }^{14}$.

\subsubsection{Consórcio Iniciativa Amazônica para a Conservação e Uso Sustentável dos Recursos Naturais (IA)}

Uma atividade muito atraente de cooperação internacional foi feita em 2004 por meio de proposta bem articulada com a participação dos países da pan-amazônia para criação da Iniciativa Amazônica com o apoio da Organização do Tratado de Cooperação Amazônica (OTCA). O principal objetivo era prevenir, reduzir, e recuperar áreas degradadas, contribuindo para a melhoria das condições de vida na região.

Para isto, busca-se elaborar e implementar programas colaborativos que identifiquem e promovam sistemas sustentáveis de uso da terra. Os membros fundadores da IA são seis empresas de pesquisa agrícola dos países amazônicos, quatro centros do CGIAR, e o IICA, por meio do Programa Procitrópicos ${ }^{15}$

As principais atividades da IA são baseadas no trabalho conjunto de comunidades de pesquisadores e articuladores das organizações locais, internacionais e governamentais. Espera-se que os resultados locais ou regionais a serem obtidos possam beneficiar a região

\footnotetext{
${ }^{14}$ Jamil Macedo, Secretário Executivo, PROCITROPICOS, IICA. Entrevista pessoal, fevereiro de 2008.

${ }^{15}$ Para detalhes vide http://www.iamazonica.org. br/home/index.php?id=conteudo.php. Consultado em 8 de fevereiro de 2008.
} 
como um todo e que "o intercâmbio de idéias e experiências entre participantes da IA ... gerará opções e esquemas que poderão ser adaptados às condições locais. Esta co-aprendizagem e diálogo melhorarão a aplicação local de opções de manejo dos recursos e aumentarão a efetividade das organizações locais e nacionais para responder e transmitir as ações de êxito"16.

\subsection{Cooperação bilateral prestada na Embrapa}

A cooperação técnica prestada pela Embrapa tem sido muito expressiva ao se analisar o número de projetos registrados na $A B C$. Considerando todas as áreas, cerca de 50\% desses projetos contam com a participação direta da Embrapa. Especificamente em agricultura, 95\% dos projetos são executados em cooperação com a Embrapa ${ }^{17}$.

Os grandes temas explorados nas atividades de cooperação internacional prestada pela Embrapa incluem intercâmbio de germoplasma, transferência de tecnologia para produção de culturas alimentares, fibras, biocombustíveis (etanol e biodiesel) e modelos institucionais de pesquisa e desenvolvimento.

\subsubsection{Produção de alimentos básicos}

A transferência de tecnologias brasileiras disponíveis poderá melhorar a produção de alimentos básicos de vários outros países com baixo nível de desenvolvimento. É o caso, por exemplo, de muitos países africanos que poderão se beneficiar e até mesmo reduzir os alarmantes níveis de pobreza predominantes na região. Isso pode ser

\footnotetext{
${ }^{16}$ Para detalhes vide (http://www.iamazonica.org.br/home/index.php?id=conheca/contexto.php). Consultado em 8 de fevereiro de 2008.

${ }_{17}$ Informações cedidas por Washington Silva, Chefe da Coordenadoria de Prospecção e Inovação, Assessoria de Relações Internacionais, Embrapa. Brasília, fevereiro de 2008.
} 
feito principalmente através de pesquisa adaptativa que permita a transferência relativamente rápida de conhecimento e produtos.

Mandioca, batata-doce, milho, sorgo, hortaliças e frutas são produtos de interesse de diversos países africanos e para as quais a Embrapa detém tecnologias simples. Os possíveis ganhos da Embrapa e do Brasil estariam vinculados à aquisição de novos materiais genéticos (variedades), a ganhos de royalties pelo uso de variedades brasileiras, à ampliação de vendas de produtos brasileiros tais como equipamentos e máquinas agrícolas nesses países.

A política de cooperação técnica do Brasil em agricultura no exterior inclui explicitamente nossos vizinhos latino-americanos, conforme declaração oficial do governo brasileiro ${ }^{18}$. Tal cooperação é recíproca de modo a unir a Embrapa aos Institutos Nacionais de Investigação Agropecuária (INIAs) da região na busca de soluções para os problemas comuns, como cultivo da batata, cultivo do alho, agricultura orgânica, bicudo do algodoeiro, recuperação de áreas degradadas, agricultura de precisão e plantio direto. Já há indicações de materialização dessas idéias. Em 2007 houve a aprovação de um projeto de melhoramento da batata entre a Embrapa e o INIA da Argentina por meio da $A B C$.

Programas e consórcios regionais são ferramentas importantes para facilitar a cooperação entre os diferentes sistemas nacionais de pesquisa agropecuária na região. Entretanto, há países que nem sequer contam com sistema organizado de pesquisa agropecuária, onde a Embrapa poderá oferecer a experiência bem sucedida de seu modelo e sua capacidade acumulada em gerência de ciência e tecnologia para o campo.

${ }^{18}$ http://www.abc.gov.br/abc/abc ctpd.asp. Consultado em 27 de fevereiro de 2008. 


\subsubsection{Escritórios Regionais da Embrapa}

A partir de 2007, a Embrapa iniciou o processo de implantação de escritórios regionais para melhor operacionalizar as atividades de cooperação técnica prestada. Em 2007 foi implantado um escritório em Acra (Gana, África) e em 2008 foi implantado outro em Caracas, Venezuela.

\subsubsection{Embrapa África}

A Embrapa recebeu do MRE e do Gabinete da Presidência da República recomendações para tomar as providências necessárias referentes à criação de um Escritório de trabalho da Embrapa na África. Dessa forma, as articulações podem ser feitas in loco, aumentando assim as possibilidades de sucesso da empreitada brasileira de apoio aos africanos nas ações de combate à fome e à pobreza.

Frente a essa convocação governamental, a Embrapa iniciou levantamento para selecionar o país e a instituição africana que iria acolher o Escritório da Empresa. O resultado final indicou Gana e a capital desse país, Acra, como o local mais adequado para o estabelecimento desse ponto focal. Contribuíram para essa decisão parâmetros técnicos, estratégicos e políticos do Governo brasileiro e da própria Embrapa. As principais razões que levaram à escolha de Gana como sede da Embrapa África foram: i) a estabilidade política do País; ii) a adoção do inglês como língua oficial, portanto de maior abrangência que os países de língua portuguesa; iii) existência de relações diplomáticas estabelecidas com o Governo brasileiro; e iv) Acordo Básico para cooperação técnico-científica assinado desde 1974.

Desde janeiro de 2007 o Escritório Regional da Embrapa na África, respaldado pelo Acordo firmado com o Instituto Internacional de 
Manejo de Água (International Water Management Institute, IWWC) do sistema CGIAR, está em atuação e encontra-se nesse momento em fase de implantação e implementação do seu Plano de Trabalho.

Quanto ao continente africano, a Embrapa tem sido prestadora de cooperação técnica e não tem se furtado a transferir conhecimentos que desenvolveu em parceria com países do primeiro mundo no âmbito da cooperação recebida, ou ainda aqueles que desenvolveu com sua equipe de pesquisadores nacionais.

Embora articulações internacionais ocorram também via sede da Embrapa, a presença física de representantes da Empresa naquele continente potencializa as atividades em andamento. A abertura da Embrapa África é uma das novas instrumentações colocadas em prática para desenvolver projetos cooperativos que sejam sustentáveis nas áreas agrícola, social, ambiental e financeira.

Cabe à Embrapa África desenvolver, em parceria com instituições africanas, projetos específicos direcionados para a prestação de assistência técnica, formação de recursos humanos e fortalecimento institucional de organizações voltadas para o desenvolvimento sustentável da agricultura, conferindo as condições necessárias para o aumento da capacidade de produção agropecuária dos países africanos.

O objetivo geral da Embrapa África é contribuir com os governos de países africanos, por meio do aporte de tecnologias e conhecimentos, nos projetos em desenvolvimento e a serem desenvolvidos por instituições do setor agropecuário, com vistas ao combate à fome e à pobreza. Esse objetivo pode ser significativamente potencializado através da triangulação ou cooperação trilateral entre países desenvolvidos, para provimento de recursos financeiros, países africanos e o Brasil. Pode também ser impulsionado por meio de um 
aprimoramento no sistema de acompanhamento na execução de projetos pelo setor de cooperação internacional da Embrapa.

\subsubsection{Embrapa Venezuela}

A Venezuela demanda fortemente cooperação para tentar conquistar sua soberania alimentar uma vez vez que dois terços dos alimentos consumidos são importados atualmente. O Governo do Brasil orientou a Embrapa para, dentro de menor prazo possível, promover ações de intercâmbio e cooperação no país vizinho.

Recentemente - fevereiro de 2008, o Governo brasileiro, por meio da Embrapa iniciou negociações com autoridades do Instituto Nacional de Investigações Agrícolas (INIA), Ministério de Agricultura e Terras e Ministério do Poder Popular das Relações Exteriores da Venezuela, visando à implantação de projeto da Embrapa nesse país. O objetivo principal do projeto é o intercâmbio de tecnologias e conhecimentos para melhorar as condições da agropecuária em ambos os países.

Especificamente, busca-se um aumento da produção de proteína animal, a implantação de modernas tecnologias agrícolas e a implantação de um plano nacional para a produção e certificação de sementes de hortaliças, grãos e forrageiras. Esses temas são considerados como altamente prioritários pelo Governo venezuelano. O Escritório da Embrapa em Caracas - a Embrapa Venezuela - contará com a presença de três pesquisadores brasileiros ${ }^{19}$.

\footnotetext{
${ }^{19}$ Informações cedidas por Washington Silva, Chefe da Coordenadoria de Prospecção e Inovação, Assessoria de Relações Internacionais, Embrapa. Brasília, fevereiro de 2008.
} 


\subsection{Cooperação bilateral prestada e recebida}

As atividades de cooperação bilateral prestada e recebida da Embrapa têm sido desenvolvidas principalmente por meio dos Laboratórios da Embrapa no exterior (Labex). Os Labex são na realidade laboratórios nos quais a Embrapa aloca um ou mais pesquisadores. A cooperação bilateral praticada pela Embrapa envolve 68 acordos assinados com 37 países e 64 instituições.

\subsubsection{Laboratórios da Embrapa no exterior - Labex}

A criação dos Labex foi decorrente das crescentes demandas da sociedade brasileira num primeiro momento. Três premissas fundamentaram sua implantação (i) a crescente importância do agronegócio, incluindo a agricultura familiar, para o desenvolvimento do país; (ii) ciência e tecnologia como insumos cada vez mais determinantes na competitividade da produção e comercialização; e, (iii) a geração de conhecimentos no mundo, inclusive em ciências agrárias e correlatas, tem origem em três grandes pólos que são os Estados Unidos, Europa e sul da Ásia (Crestana \& Magalhães, 2007).

O Labex Estados Unidos foi criado em 1998 e o Labex França em 2002. Nos Estados Unidos, o Labex foi instalado com o apoio do Serviço de Pesquisa Agrícola (ARS), do Departamento de Agricultura (USDA). O Labex Estados Unidos trabalha para fortalecer e ampliar a cooperação científica e tecnológica entre os pesquisadores das duas instituições e de universidades brasileiras e americanas. Já o Labex Europa representa a presença física da Embrapa na Europa, por meio de convênio com a Agrópolis, Montpellier, França, e com a Universidade de Wageningen, Holanda. Assim, o Labex Europa é referido como Labex Europa - Montpellier e Labex Europa - Wageningen. 
Com isso, o Brasil tornou-se o primeiro país em desenvolvimento, do Hemisfério Sul, a ter um laboratório na Europa, junto a centros de excelência em ciência e tecnologia, aplicadas à agricultura tropical. Além disso, a Embrapa está discutindo a possibilidade de ampliar o Labex Europa por meio de um convênio com o Norwich Research Park, Norwich, Inglaterra.

A seguir, será feita uma abordagem sobre a cooperação técnica prestada e recebida pela Embrapa separadamente.

\subsection{Cooperação bilateral recebida}

A cooperação bilateral recebida envolve atividades com países desenvolvidos e é caracterizada como uma ferramenta promotora de mudanças por meio de transferência de tecnologia. A consequência principal é a incorporação de conhecimentos que somem ao desenvolvimento do País.

Os principais objetivos da cooperação bilateral recebida são o aperferfeiçoamento da capacidade técnica de gerenciamento, o acompanhamento e a execução de projetos, a divulgação de oportunidades e resultados da cooperação técnica bilateral recebida, a coordenação de programas de cooperação técnica com governos de países industrializados, o fortalecimento das ações atuais, a melhoria da qualidade do acompanhamento dos programas e projetos e o incremento das parcerias com as agências de desenvolvimento internacional.

A cooperação bilateral recebida é realizada por meio de consultorias de alto nível, capacitação e treinamento de técnicos brasileiros e, em alguns casos, pela doação de equipamentos de alta tecnologia, com o objetivo final de transferir novos conhecimentos às 
instituições brasileiras ${ }^{20}$.

Os recursos aportados pelas fontes externas bilaterais são a fundo perdido e correspondem, em média, a 50\% do valor da cooperação solicitada. A contrapartida oferecida deve ser, no mínimo, igual ao valor da cooperação solicitada, e deverá ser calculada levando em consideração os gastos com salários da equipe que participará diretamente da execução do projeto, a infra-estrutura colocada à disposição do projeto, os gastos com seminários e estágios, dentre outros insumos.

A cooperação recebida envolve intercâmbio de germoplasma, biologia avançada, sustentabilidade ambiental, mudanças climáticas, sanidade animal e vegetal, agroenergia, agricultura de precisão e tecnologias agro-alimentares. A seguir serão dados dois exemplos de cooperação bilateral recebida, o caso da soja e o programa de sustentabilidade Brasil-Itália.

\subsubsection{O caso da soja}

A soja foi originalmente introduzida no Brasil no final do século 19. Muito embora não tenha havido sucesso, essas tentativas de cultivo pavimentaram o caminho para uma nova iniciativa do missionário norte-americano Alberth Lehenbauer. Ele trouxe uma pequena quantidade de grãos dos Estados Unidos e passou a difundir essa cultura entre os agricultores da região de Santa Rosa (RS), iniciando então seu verdadeiro cultivo no Brasil.

O progresso alcançado no País foi notável. Uma das principais razões do desenvolvimento dessa cultura com altos índices de produtividade foi o melhoramento genético realizado em território

${ }^{20}$ http://www.abc.gov.br/abc/abc ctrb.asp. Consultado em 12 de março de 2008. 
brasileiro que possibilitou sua expansão para as regiões Centro-Oeste e Nordeste.

Em 1973, quando a Embrapa foi criada, a pesquisa com a soja continuou. Na ocasião, a soja era uma cultura ainda incipiente no País, praticamente restrita aos estados da Região Sul. A Embrapa Trigo assumiu os estudos de melhoramento genético de soja visando atender aos produtores daquela região. Nos anos posteriores os estudos foram ainda mais arrojados em decorrência da criação da Embrapa Soja no Paraná (Embrapa Soja, 2004).

A história da soja no Brasil pode ser resumida em três passos marcantes. Primeiro, foi a introdução do cultivo da soja propriamente dita. Em seguida, veio a fase dos resultados dos trabalhos de melhoramento, envolvendo cruzamentos genéticos realizados localmente, em substituição à prática pioneira de simples introdução de variedades estrangeiras. Num terceiro momento, a importância do melhoramento genético ficou patente. O aparecimento de inúmeras doenças foi contornado através do desenvolvimento de variedades resistentes que substituíram aquelas plantadas até então.

Hove então no âmbito doméstico o "estabelecimento de uma bem articulada rede de pesquisa de soja envolvendo os poderes públicos federal e estadual, apoiada financeiramente pela indústria privada (Swift, Anderson Clayton, Samrig, etc)" (Embrapa Soja, 2004).

O sucesso da soja no Brasil é um exemplo bem sucedido de cooperação internacional. O desenvolvimento da pesquisa com essa cultura tem marcado a atuação da Embrapa desde sua criação há 34 anos até os dias atuais. Essas relações permitiram à Empresa incorporar experiências de outros países - Estados Unidos e Japão, principalmente - relacionadas a sistemas organizacionais, capacitação de 
pesquisadores, estruturação de bases físicas e laboratoriais, organização e aperfeiçoamento de programas de pesquisa.

\subsubsection{O exemplo do programa de biodiversidade Brasil - Itália}

A cooperação bilateral entre o Brasil e a Itália foi lançada em meados de 2002 por meio do Programa Biodiversidade Brasil-Itália (PBBI). O PBBI foi criado para apoiar os esforços do governo brasileiro e das comunidades rurais envolvidas em facilitar a conservação ambiental e o uso sustentável dos recursos fitogenéticos brasileiros de interesse agroalimentar e industrial.

Seu objetivo foi - e ainda é - contribuir para a redução da pobreza e melhorar as condições de vida e alimentação da população local, por meio da conservação e agregação de valor à biodiversidade nativa e agrícola no Brasil. As instituições envolvidas são o Istituto Agronomico per l'Oltremare (IAO), do lado italiano, e do lado brasileiro a execução é compartilhada pela Embrapa e pelo Instituto Chico Mendes de Conservação da Biodiversidade (ICMBio). Em 2008, o PPBI encerrou seu segundo ano de execução trienal e inicia o terceiro e último ano, com conclusão prevista para março de 2009.

O foco do Programa é nas comunidades tradicionais agroextrativistas e indígenas, bem como de pequenos agricultores e assentados da Reforma Agrária, que têm baixos índices de desenvolvimento sócio-econômico e habitam áreas protegidas e zonas florestais ou rurais do cerrado, da caatinga e da amazônia, no interior do Brasil. O Programa está baseado na interação dessas populações com as espécies vegetais nativas e endêmicas, bem como as de cultivo tradicional e local, que tenham relevância ou potencial para a segurança alimentar e a geração de renda. Sua estratégia é promover a conservação, uso sustentável e agregação de valor e melhorias dos 
recursos fitogenéticos. Para isso, realiza atividades de pesquisa e desenvolvimento, formação e capacitação e promoção da inserção no mercado, sempre apoiadas em metodologias participativas, intercâmbio de informações e experiências, resgate e valorização da cultura tradicional.

Para o triênio de execução - 2006 a 2009 - o Programa recebeu uma dotação de cerca de 3,5 milhões de euros da Itália e contrapartidas do Brasil em termos de pessoal, serviços e infra-estrutura das agências executoras e parceiros locais. Todos os projetos componentes do PBBI trabalham em parceria com organizações locais, regionais ou nacionais, tanto governamentais como não-governamentais e movimentos sociais, bem como universidades e instituições de pesquisa brasileiras e italianas ${ }^{21}$.

\subsection{Considerações sobre as operações da cooperação técnica internacional na Embrapa}

É evidente que há um grande potencial de desenvolvimento de da cooperação técnica bilateral e multilateral por meio dos esforços já realizados pela Embrapa. No entanto a alocação de recursos humanos e financeiros para assegurar a eficiência do setor ainda é bastante tímida e deve ser aprimorada como resultado de estudos aprofundados para tomada de decisões baseadas na importância estratégica que os potenciais países cooperantes possam representar para a agricultura brasileira.

Nas atividades de cooperação envolvendo material genético brasileiro, há necessidade de aprimorar o sistema de autorização de acesso de modo a torná-lo mais ágil. A principal razão é que em alguns casos o andamento das pesquisas é muito prejudicado pela

${ }^{21}$ Programa Biodiversidade Brasil - Itália (2006-2009). 
lentidão do processo de concessão de autorização e pela própria falta de informação básica sobre o tema por parte dos pesquisadores envolvidos. 


\section{Capítulo 4 \\ Conclusão}

As relações entre os países foram fortemente afetadas pelo advento da globalização ditada pelas grandes transformações econômicas que o mundo tem experimentado principalmente nas duas últimas décadas. Um resultado palpável disso foi a percepção da necessidade de cooperação técnica entre os países. A efervescência na busca de cooperação em diferentes níveis reforça essa hipótese. O cenário na área agrícola é o mesmo.

Os países em desenvolvimento passam por transformações sem precedentes na sua história. Uma das mudanças mais impressionantes refere-se aos hábitos alimentares das populações desses países. Há um forte aumento de dietas ricas em proteínas enquanto que nos países ricos cada vez mais aumenta a demanda por alimentos funcionais e de alta qualidade. No Brasil, os dois fenômenos ocorrem simultâneamente.

As atividades de cooperação técnica prestada e recebida servem como um instrumento da política externa brasileira e poderia beneficiar a Embrapa. Esses benefícios estão relacionados principalmente à incorporação de novos conhecimentos advindos da troca de experiência entre cientistas e à aquisição de novas espécies e variedades de plantas e raças de animais mais produtivas por meio de intercâmbio de material genético.

A Embrapa acumulou uma vasta experiência em agricultura tropical nas últimas décadas. Por isso, hoje desfruta de um prestígio internacional indiscutível e recebe uma forte demanda em cooperação técnica, principalmente envolvendo transferência de tecnologia. 
Os avanços na cooperação internacional praticada pela Embrapa não têm seguido um modelo sistemático. Mesmo assim, há progressos expressivos. A participação da Empresa é cada vez mais marcante nos mecanismos propostos pelo sistema CGIAR, no sentido de privilegiar e intensificar os trabalhos no âmbito dos Sistema Nacionais de Pesquisa Agrícola (National Agricultural Research Systems, NARS).

Isso tem sido feito por meio de arranjos como os Programas Desafio (Generation Challenge Programme, GCP), em que a Embrapa é o único NARS que participa dos três programas já em implementação (Water \& Food, Generation, Harvest Plus) e está sendo convocada para participar como um importante parceiro no Programa Desafio para o Sub-Sahara.

Outro exemplo é o destaque das participações em iniciativas regionais constituídas pelos países latino-americanos coordenadas pelo IICA pelas ações do Procisul e do Procitrópicos. Mais recentemente, destacou-se o caso da Iniciativa Amazônica em que a participação proativa da Embrapa cumpre um papel de significativa importância nas aspirações de liderança geopolítica que o Brasil acalenta.

No entanto, o exercício dessa cooperação prestada, num arranjo triangular, depende de mais criatividade na interação com outros órgãos do Governo brasileiro e com organismos das Nações Unidas. É imprescindível que se explore a infra-estrutura administrativa e operacional existente nos países em desenvolvimento no delineamento de uma triangulação construtiva. Neste caso, um país industrializado reconhece a capacidade existente na Embrapa e apóia a transferência de sua tecnologia em prol do desenvolvimento de um terceiro país, cobrindo os custos dessa operação. 
Outra possibilidade é o estabelecimento de parceria com empresas brasileiras operando no exterior, a exemplo da Petrobras em Angola, da Companhia Vale do Rio Doce (CVRD) em Moçambique, e da Odebretch no Peru e no Equador (Barbosa \& Costa, 2005).

Atualmente, as prioridades na transferência de tecnologias brasileiras estão centradas nas áreas de produção de alimentos básicos e agroenergia (etanol e biodiesel). A produção de etanol é uma das iniciativas brasileiras que contribuem para o desenvolvimento sustentável, uma vez que representa uma fonte de energia limpa e renovável. Essa definição de "limpeza" tem sido contestada por ambientalistas. Eles afirmam que o custo ambiental de produção do etanol seria tão ou mais alto que o custo ambiental decorrente do uso de combustíveis fósseis.

Hoje os grandes desafios da pesquisa agrícola brasileira estão relacionados a áreas crucias que demandam intensa interação visando à cooperação com outros países. O foco deve estar centrado na recuperação e utilização de áreas degradadas de forma sustentável. Por exemplo, no desenvolvimento de variedades resistentes a doenças e à seca, no uso sustentável de florestas úmidas, na integração lavourapecuária-floresta, nas parcerias público-privadas, bioenergia (etanol, biodiesel) e no diálogo norte-sul-sul.

Num plano geral, a cooperação internacional somente será exercitada em sua plenitude à medida que a apropriação e a sustentabilidade sejam asseguradas de modo a promover 0 "fortalecimento da capacidade dos governos para gerenciar estrategicamente os processos de desenvolvimento" (Lopes, 2005).

A atuação da Embrapa em cooperação internacional prestada e recebida necessita passar por uma revisão para migrar de uma postura reativa e para uma postura proativa. Normalmente, a atuação da Assessoria de Cooperação Internacional da Embrapa tem se 
concentrado no atendimento das demandas apresentadas pelos países. É também necessário que o sistema de acompanhamento técnico e financeiro na execução de projetos de cooperação seja reavaliado e reformulado.

É importante a adoção de um sistema claro de atribuição de prioridades para tratamento de cada país de acordo com os interesses brasileiros. Nos países desenvolvidos essa classificação quanto à prioridade é exercitada fortemente. Muitas vezes de forma não tão explícita. No nosso caso, é necessário estabelecer um priorização rigorosa dos países quanto aos reais interesses da Embrapa e do Brasil para alocação do tempo do pessoal técnico envolvido e dos recursos destinados a cada caso.

É muito comum que acordos - memorandos de ententimento - entre a Embrapa e instituições de outros países sejam assinados e fiquem parados sem que nenhuma ação seguinte seja tomada. Muitas vezes os prováveis projetos de cooperação técnica que comporiam o memorando de entendimento nem chegam a ser propostos, por falta de uma atuação mais ativa de nossa parte. Essa descontinuidade pode estar relacionada com a pouca disponibilidade de recursos e com uma comunicação inadequada entre os pesquisadores das instituições envolvidas. Alguns obstáculos que se verificam na execução dos projetos podem ainda estar ligados à deficiência de um correto acompanhamento na sua execução.

Como a área de cooperação técnica internacional tem se tornado muito demandada pelos países e pelo Geverno federal nos últimos anos, é imprescindível que a Embrapa amplie seu quadro de técnicos da Assessoria de Relações Internacionais. É difícil conceber qualquer manutenção de competência com apenas um técnico para 
supervisionar a cooperação com países desenvolvidos, um para cooperação multilateral, um para a África e um para América Latina. 


\section{Referências bibliográficas}

AGÊNCIA BRASILEIRA DE COOPERAÇÃO. Histórico da Cooperação Técnica Brasileira. http://www.abc.gov.br/ct/historico ct.asp.

AYENSU, E. Statement. Technology in Society, Volume 19, Issue 1, January 1997, Pages 33-35.

BARBOSA, S.; COSTA. S. Cooperação Internacional. Revista Agronalysis. Vol 25 no. 4 p.14 -15. A Revista de Negócios da Fundação Getúlio Vagas. Especial Embrapa - Na Fronteira do Conhecimento. 2005.

CERVO, A. Socializando o desenvolvimento; uma história da cooperação técnica internacional do Brasil. Revista Brasileira de Política Internacional, 37: 37-63. 1994.

CRESTANA, S.; MAGALHÃES, B. A cooperação técnica na política externa do Brasil em agricultura: o papel da Embrapa. Cooperação Técnica na Política Externa. Realizações e Desafios. Fundação Alexandre de Gusmão. Agência Brasileira de Cooperação. 2007. 15p.

EMBRAPA SOJA. Tecnologias de Produção de Soja Região Central do Brasil. Sistema de Produção, No 1. 2004.

http://www.cnpso.embrapa.br/producaosoja/SojanoBrasil.htm.

FONSECA, L.H.P. 20 Anos da Agência Brasileira de Cooperação - ABC. Cooperação Técnica na Política Externa. Realizações e Desafios. Fundação Alexandre de Gusmão. Agência Brasileira de Cooperação. 2007. 14p.

INOUE, C.Y.A.; APOSTOLOVA, M.S. A cooperação internacional na política brasileira de desenvolvimento. Associação Brasileira de 
Organizações Não-Governamentais (ABONG). Núcleo Animação Terra e Democracia. 51p. 1995.

LOPES, C. Cooperação e Desenvolvimento Humano: a agenda emergente para o novo milênio. Editora UNESP. São Paulo. 210p. 2005

MINSTÉRIO DAS RELAÇÕES EXTERIORES. Os Caminhos do Agronegócio Brasileiro.

http://www.itamaraty.gov.br/cdbrasil/itamaraty/web/port/economia/agric/caminhos/index.htm.

VERENHITACH, G. D.; DEITOS, M.A.; SEITENFUS, R. O Brasil e a cooperação triangular Sul-Sul para o desenvolvimento: o caso do Haiti. I Simpósio em Relações Internacionais do Programa de Pósgraduação em Relações Internacionais San Tiago Dantas (Unesp, Unicamp e Puc-Sp). 16p. 2007.

VAZ, A.; INOUE, C.Y.A. Funding international development: The role of emerging economies. The Brazilian case. Edited draft version $1 \mathrm{D}$. Rwolands. 2007. 47p. 


\section{Siglas}

$A B C$

AGROFUTURO

ARS

BID

BIRD

CAN

CGIAR

Research

CTPD

Desenvolvimento

CVRD

EMBRAPA

FAO

FUNIM

GCP

IA

IBAS

ICMBio

IICA

Agricultura

INIAS

ITTO

IWWC

JICA
Agência Brasileira de Cooperação

Programa de Inovação Tecnológica e Novas Formas de Gestão da Pesquisa Agropecuária

Serviço de Pesquisa Agrícola do USDA

Banco Interamericano de Desenvolvimento

Banco Mundial

Comunidade Andina da Nações

Consultative Group on International Agricultural

Cooperação Técnica entre Países em

Companhia Vale do Rio Doce

Empresa Brasileira de Pesquisa Agropecuária

Organização da Nações Unidas para a Alimentação

Fundo Multilateral de Investimentos

Generation Challenge Programme

Consórcio Iniciativa Amazônica para a Conservação e Uso Sustentável dos Recursos Naturais (= Iniciativa Amazônica)

Fórum India-Brasil-África do Sul

Instituto Chico Mendes de Conservação da

Biodiversidade

Instituto Interamericano de Cooperação para a

Institutos Nacionais de Investigação Agropecuária

International Tropical Timber Organization

(Organização Tropical Internacional da Madeira)

International Water Management Institute

(Instituto Internacional de Manejo de Água)

Agência Japonesa de Cooperação Internacional 


\begin{tabular}{|c|c|}
\hline LABEX & Laboratórios da Embrapa no Exterior \\
\hline MDG & $\begin{array}{l}\text { Millennium Development Goal } \\
\text { (Programa de Desenvolvimento do Milênio das } \\
\text { Nações Unidas) }\end{array}$ \\
\hline MRE & Ministério das Relações Exteriores \\
\hline NARS & $\begin{array}{l}\text { National Agricultural Research Systems } \\
\text { (Sistemas Nacionais de Pesquisa Agrícola) }\end{array}$ \\
\hline NEPAD & Nova Parceria para o Desenvolvimento Africano \\
\hline ONU & Organização das Nações Unidas \\
\hline OTCA & Organização do Tratado de Cooperação Amazônica \\
\hline PD\&l & Pesquisa, Desenvolvimento e Inovação \\
\hline PIB & Produto Interno Bruto \\
\hline PROCISUL & $\begin{array}{l}\text { Programa Cooperativo para o Desenvolvimento } \\
\text { Tecnológico Agropecuário do Cone Sul }\end{array}$ \\
\hline PROCITRÓPICOS & $\begin{array}{l}\text { Programa Cooperativo de Investigação e } \\
\text { Transferência de Tecnologia para os Trópicos Sul }\end{array}$ \\
\hline PRODETAB & $\begin{array}{l}\text { Projeto de Apoio ao Desenvolvimento de Tecnologias } \\
\text { Agropecuárias para o Brasil }\end{array}$ \\
\hline PROETA & $\begin{array}{l}\text { Programa de Apoio ao Desenvolvimento de Novas } \\
\text { Empresas de Base Tecnológica Agropecuária e à } \\
\text { Transferência de Tecnologia }\end{array}$ \\
\hline SNPA & Sistema Nacional de Pesquisa Agropecuária \\
\hline USDA & Departamento de Agricultura dos Estados Unidos \\
\hline
\end{tabular}

